\title{
AVALIAÇÃO DO USO DE DADOS AEROGEOFÍSICOS PARA MAPEAMENTO GEOLÓGICO E PROSPECÇÃO MINERAL EM TERRENOS INTEMPERIZADOS: 0 EXEMPLO DE SERRA LESTE, PROVÍNCIA MINERAL DE CARAJÁS
}

\author{
Thais Andressa Carrino, Carlos Roberto de Souza Filho e Emilson Pereira Leite \\ Recebido em 11 julho, 2007 / Aceito em 28 setembro, 2007 \\ Received on July 11, 2007 / Accepted on September 28, 2007
}

\begin{abstract}
The Amazon region is characterized by dense equatorial forest, thick soil cover and rainy weather. This makes airborne geophysics a key tool for lithologic and structural mapping and improvement of preexisting geological maps. This paper presents an application study of airborne magnetic and gamma-ray spectrometric data in the Serra Leste region, Carajás Mineral Province, providing discussions about the geophysical signatures of specific lithologies and strategies to constrain favorable targets for exploration of Au-Pd-Pt, Cr-PGE, Cu-Mo-Au and Fe deposits.
\end{abstract}

Keywords: airborne geophysics, geological characterization, mineral exploration, Carajás Mineral Province.

RESUMO. A região Amazônica é caracterizada por floresta equatorial densa, espessa cobertura de solos e clima chuvoso. Este contexto torna os aerolevantamentos geofísicos ferramentas-chave para mapeamentos litológicos e estruturais e para revisão de mapas geológicos pré-existentes. Este artigo apresenta um estudo de aplicação de dados gamaespectrométricos e magnetométricos na região de Serra Leste, Província Mineral de Carajás, proporcionando discussões sobre as assinaturas geofísicas de litotipos específicos e estratégias para realce de alvos favoráveis à exploração de depósitos de Au-Pd-Pt, Cr-EGP, Cu-Mo-Au e Fe.

Palavras-chave: aerogeofísica, caracterização geológica, exploração mineral, Província Mineral de Carajás. 


\section{INTRODUÇÃO}

A utilização de geotecnologias tem subsidiado crescentemente campanhas de mapeamento geológico e exploração mineral (e.g., Souza Filho \& Crósta, 2003; Almeida et al., 2003; Crósta et al., 2003; Silva et al., 2003). Condições como densa vegetação de grande porte, espessos perfis de solos e clima chuvoso ilustram algumas das freqüentes adversidades naturais associadas a terrenos tropicais e equatoriais úmidos. Estas são variáveis que dificultam campanhas de reconhecimento geológico por métodos tradicionais baseados exclusivamente em trabalhos de campo.

0 objetivo desse trabalho é demonstrar, em uma área teste inserida no domínio da floresta equatorial ombrófila densa (Floresta Amazônica), o papel de dados magnetométricos e gamaespectrométricos processados como auxílio à cartografia geológica e à caracterização de alvos prospectivos. Para tanto, interpretações de dados aerogeofísicos de alta densidade foram conduzidas na região de Serra Leste, localizada na Província Mineral de Carajás (PMC), porção sudeste do Estado do Pará, a fim de discutir as contribuições provenientes destes dados como primeiro passo ao reconhecimento geológico em terrenos intensamente intemperizados. A área de estudo localiza-se nas proximidades das cidades de Marabá, Eldorado dos Carajás e Parauapebas, abrangendo 0 município de Curionópolis (Fig. 1). 0 principal acesso rodoviário é realizado pela PA-150. 0 contexto geomorfológico caracterizase pela presença de serras e platôs com altitudes que superam 700 metros.

\section{ARCABOUÇO GEOLÓGICO}

A Província Mineral de Carajás (PMC), compreendida no Cráton Amazônico, apresenta complexa trama geológica-estrutural e diversificados depósitos minerais, sendo, desta maneira, denominada de Província Polimetálica de Carajás (Dardenne \& Schobbenhaus, 2000). A área alvo do estudo, a região de Serra Leste, está inclusa na PMC, mais especificadamente na porção norte, caracterizada pelo Cinturão de Cisalhamento Itacaiúnas (Pinheiro \& Holdsworth, 2000), onde insere-se a Serra de Carajás. Três eventos deformacionais regionais foram constatados neste domínio: (i) o primeiro evento (> 2,8 Ga) é marcado por zonas de cisaIhamento de direção $\mathrm{E}-\mathrm{W}$, estruturas transtrativas e terminações 'rabo de cavalo' (e.g., de Serra Pelada, com direção NNE-SSW); (ii) 0 segundo evento ( 2,8 a 2,65 Ga) está associado ao cisalhamento transcorrente dextral-oblíquo na direção WNW-ESE, de natureza rúptil-dúctil a dúctil; (iii) 0 terceiro evento ( 2,6 a 1,88 Ga) é caracterizado por movimentos transpressivos que formaram estruturas rúpteis e rúpteis-dúcteis, com reativação de antigas falhas, como a Zona de Cisalhamento Transcorrente Cinzento (ZCTC), gerando movimentação sinistral (Veneziani et al., 2004).

A Figura 2 mostra 0 mapa geológico da área de estudo na região de Serra Leste, que perfaz cerca de $695 \mathrm{~km}^{2}$. Resumidamente, esta região é caracterizada pelas seguintes unidades geológicas:

- Complexo Xingu: consiste no embasamento composto por rochas gnáissicas, migmatíticas e granitóides, com idade em torno de 2,8 Ga (Villas \& Santos, 2001). Rochas desse complexo afloram, principalmente, na porção sul da área de estudo (Fig. 2).

- Grupo Rio Novo: é caracterizado por uma assembléia de anfibolitos, xistos, metagrauvacas, formações ferríferas, além de litotipos como rochas máficas e ultramáficas (Villas \& Santos, 2001). Sua ocorrência majoritária é na porção central da área.

- Complexo Luanga: intrude o Grupo Rio Novo; compreende corpos em formato de sills com idade de cerca de 2,76 Ga. Abrange rochas como peridotitos, dunitos, leucogabros e noritos (Dardenne \& Schobbenhaus, 2001), os quais afloram no setor leste da área.

- Formação Águas Claras: anteriormente denominada de Grupo Rio Fresco (Docegeo, 1988), é caracterizada, principalmente, por quartzitos, metassiltitos, metaconglomerados e marga dolomítica (Tallarico et al., 2000), com idade em torno de 2,6 Ga. É representativa, sobretudo, na porção noroeste da região de Serra Leste (Fig. 2).

- Granitos arqueanos: são representados pelo Granito Estrela, que ocupa a parte nordeste da região de Serra Leste. Esse granito tem idade em torno de 2.76-2.74 Ga (Dall'Agnol et al., 1997; Barros et al., 2001) e é caracterizado por rochas de composição monzogranítica a sienogranítica.

- Granitos anorogênicos: são representados pelo Granito Cigano na porção extremo oeste da área, que corresponde a um batólito de composição alcalina a sub-alcalina, de idade Paleoproterozóica ( 1,88 Ga) (Dall'Agnol et al., 1994).

- Diques básicos: os diques, gabróicos em geral, possuem direção norte-sul e cortam praticamente todas as unidades acima citadas na região (Pinheiro \& Holdsworth, 2000). Sua idade é incerta. 

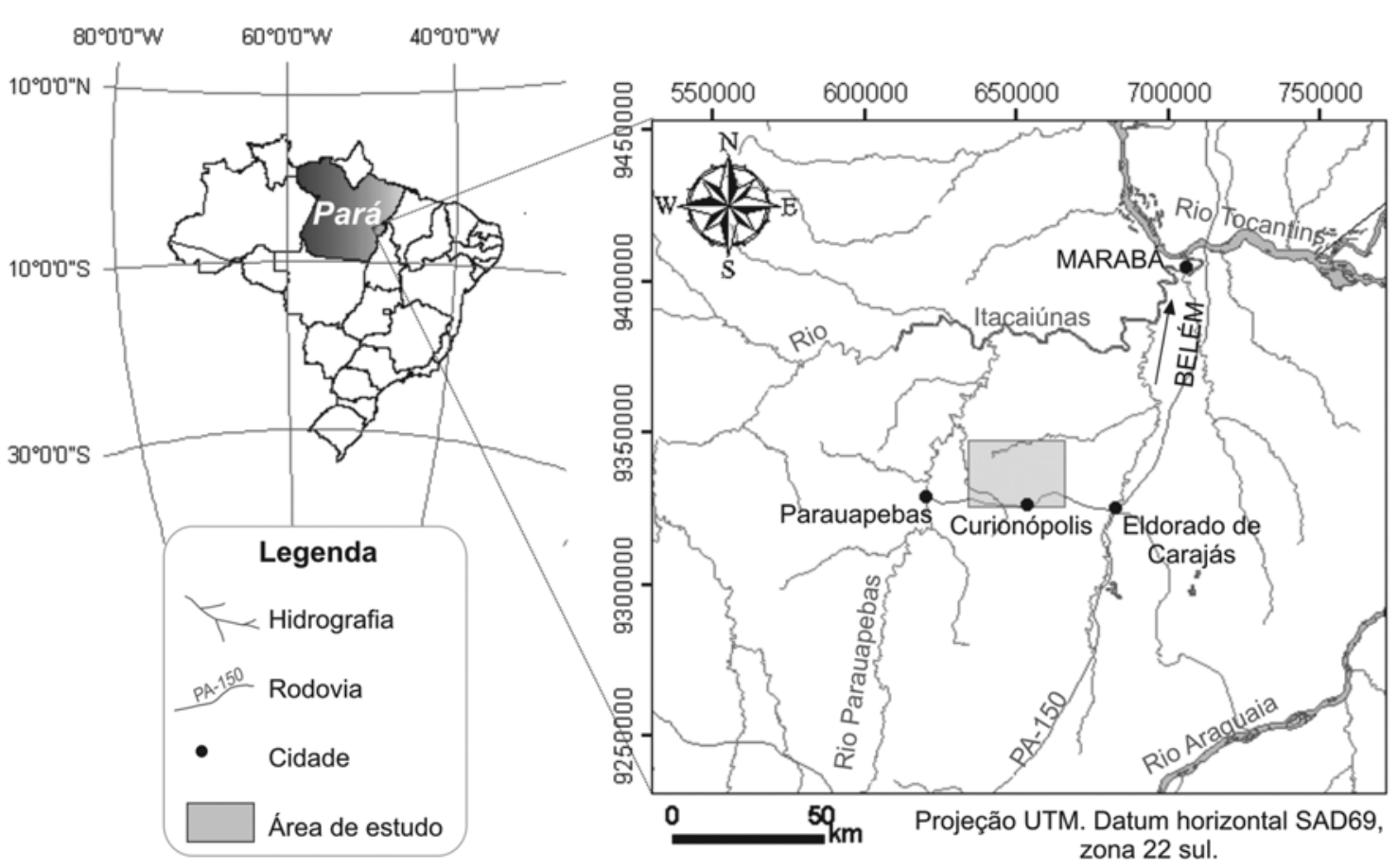

Figura 1 - Localização da área de estudo.

- Coberturas recentes: representam coberturas supergênicas (lateríticas, ferríferas e latossolos), com distribuição nas áreas de abrangência dos depósitos de Serra Leste e Serra Pelada, principalmente (Nunes, 2002).

A região de Serra Leste também é caracterizada por diversificados depósitos minerais, destacando-se Serra Pelada (Au-Pd-Pt), Luanga (Cr-Elementos do Grupo da Platina (EGP)), Serra Verde (Cu-Mo-Au) e Serra Leste (Fe) (Fig. 2).

0 depósito de Serra Pelada foi intensamente explorado na década de 80 devido à existência de mineralizações auríferas concentradas e remobilizadas por eventos supergênicos. A área do depósito é caracterizada por rochas do Grupo Rio Novo intrudidas pelo Complexo Luanga e, mais ao topo, seqüências metassedimentares da Formação Águas Claras que compreendem as rochas hospedeiras de Au-(Pd-Pt). A mineralização é epigenética e estruturalmente controlada por dobras e falhas. A disposição das mineralizações de ouro segue 0 contato entre a marga doIomítica e os metassiltitos carbonosos, havendo uma zona silicificada envolta dos corpos mineralizantes. Os fluidos hidrotermais interagiram com a marga dolomítica e intrusões dioríticas, resultando na precipitação de sulfetos disseminados. Postula-se, como possíveis fontes de Pd-Pt, as intrusões dioríticas ou as rochas máficas e ultramáficas (Tallarico et al., 2000).
0 depósito estratiforme e de filiação magmática Luanga está inserido no complexo homônimo que consiste em corpos de filiação toleítica intrusivos no Grupo Rio Novo. A porção inferior é caracterizada por dunitos, peridotitos e ortopiroxenitos (conjunto marcado por presença de magnetita devido a processos de alteração de olivinas), passando a noritos/leucogranitos na parte superior. Destacam-se as mineralizações de cromititos nos ortopiroxenitos (Suita, 1988), havendo ainda enriquecimento em EGP, sendo os minerais mais comuns arsenietos, ligas metálicas, metais nativos e raros sulfetos. Estas espécies podem estar inclusas na cromita e englobadas em silicatos serpentinizados, disseminados em ganga silicática alterada em associação com sulfetos (pirrotita, pirita, calcopirita, entre outros) (Dardenne \& Schobbenhaus, 2001).

Serra Verde compreende um depósito arqueano cupro-aurífero de pequeno porte e pobre em óxido de ferro, 0 que 0 torna único na região de Carajás. Três eventos hidrotermais caracterizam a história evolutiva relacionada a esse depósito: (i) origem do Grupo Rio Novo (hospedeiras), em associação à hidrotermalismo submarino simultâneo à mineralização; (ii) fluxo de fluidos hidrotermais devido à intrusão do Complexo Granítico Estrela; (iii) circulação de fluido ao longo de planos de fratura durante cisalhamento. Diques proterozóicos, de composição gabro-diorítica, cortam 0 depósito (Villas \& San- 

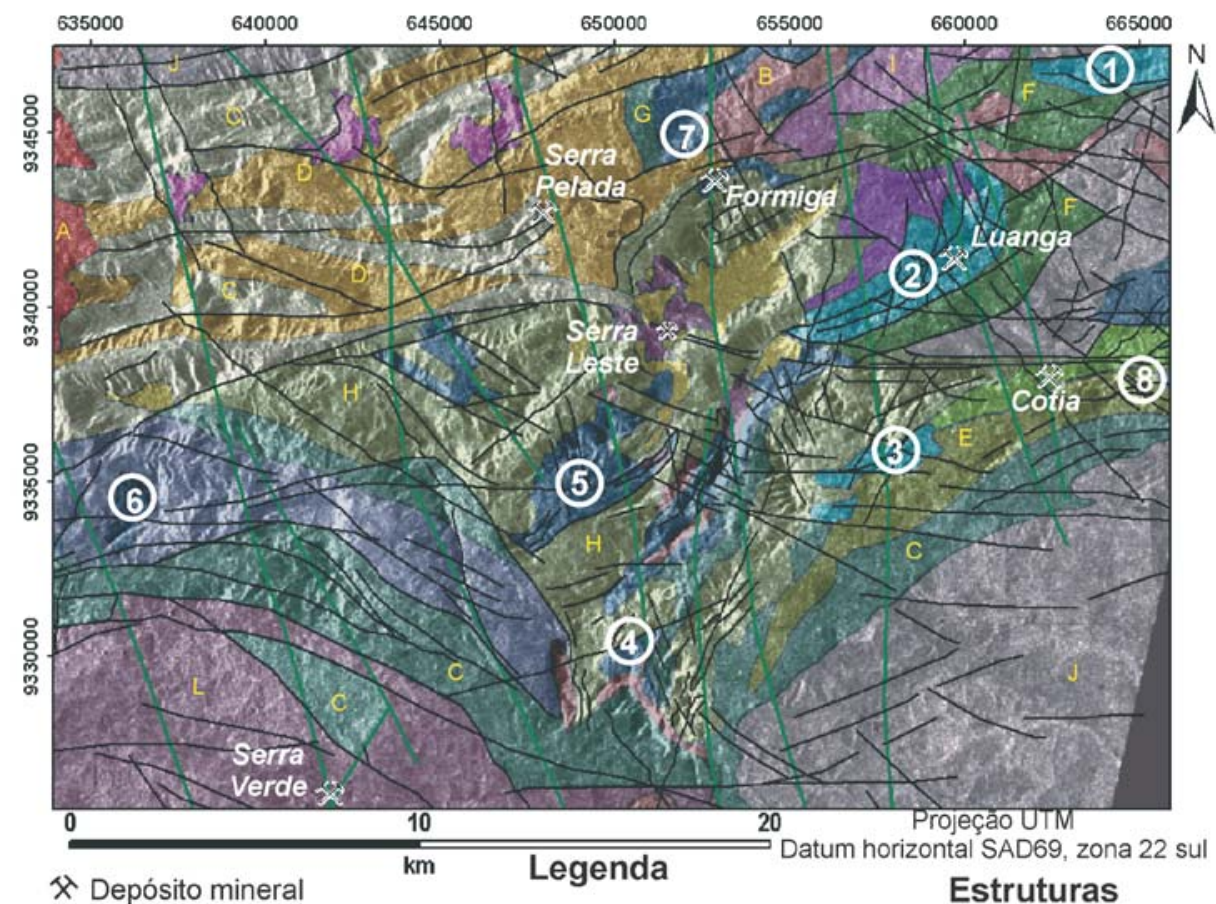

Unidades litlológicas
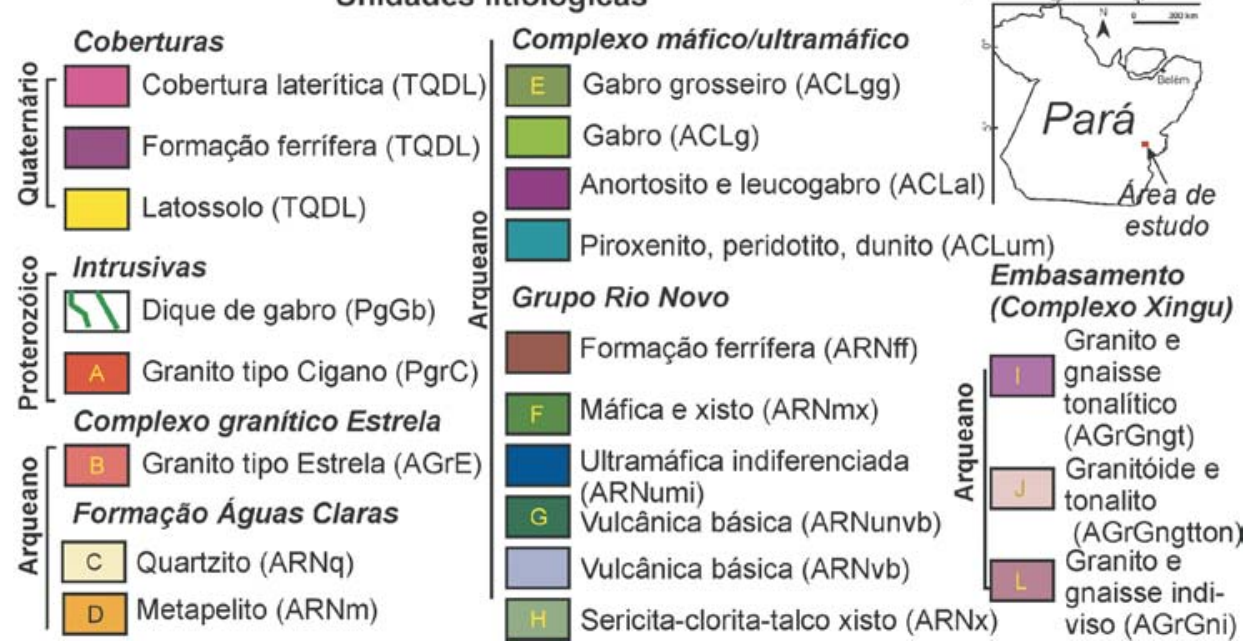

Figura 2 - Mapa geológico simplificado de Nunes (2002). Complexos máficos/ultramáficos presentes são: 1 - Luanga Norte; 2 - Luanga; 3 - Luanga Sul; 4 - Afrodite; 5 - Órion; 6 - Centauro (nomenclatura apresentada em Nunes, 2002); 7 - Formiga; 8 - Pégasus.

tos, 2001). As mineralizações ocorrem em lentes de sulfeto maciço, concordantes a sub-concordantes ao acamamento das hospedeiras, e de forma disseminada. 0 corpo maciço é composto por duas lentes decamétricas com $70 \%$ de sulfeto. 0 minério é representado por calcopirita e, em menor quantidade, por pirrotita, pirita, esfalerita, molibdenita, além de minerais de ganga (quartzo, anfibólio, entre outros). Villas \& Santos (2001) postularam uma origem associada à formação de um depósito do tipo vulcanogênico (VMS). Marschik et al. (2005) obtiveram uma idade Re-0s de $2.609 \pm 13$ Ma para molibdenita de Serra Verde, o que, de acordo com estes autores, sugere uma relação genética com granitóides alcalinos de 2,56 a 2,76 Ga ou com magmatismo do tipo arco vulcânico (2,6 a 2,7 Ga).

A região de Serra Leste é marcada também por depósitos de ferro de alto teor, similares àqueles de Serra Norte e Serra Sul 
(Dardenne \& Schobbenhaus, 2001), explorados pela Companhia Vale do Rio Doce (CVRD) (CVRD, 2007). Este conjunto de alvos é caracterizado, em superfície, por crostas ferruginosas geradas por intemperismo químico de formações ferriferas e rochas vulcânicas. Geomorfologicamente, os depósitos da região de Carajás (e.g., N4, N2, S11, entre outros) correspondem a platôs cuja topografia é mantida por uma cobertura de canga ou crosta ferruginosa espessa e dura, que compreende o minério laterítico (Lindenmayer et al., 2001).

\section{MATERIAIS}

Dados gamaespectrométricos e magnetométricos foram obtidos em 1993 e 1999, respectivamente, e realizados para a CVRD. Os primeiros dados foram adquiridos pela Geomag, sendo caracterizado por espaçamentos das linhas de vôo (N-S) e de controle (E-W), respectivamente, de $250 \mathrm{~m}$ e $5000 \mathrm{~m}$. 0 aerolevantamento magnetométrico foi realizado pela Geoterrex-Dighem, com espaçamento das linhas de vôo (N-S) de $250 \mathrm{~m}$ e das linhas de controle (E-W) de $6000 \mathrm{~m}$. Dados altimétricos do Shuttle Radar Topography Mission (SRTM), com resolução espacial aproximada de $90 \mathrm{~m}$, também foram empregados no estudo.

\section{PROCESSAMENTO DOS DADOS AEROGEOFÍ́SICOS}

0 modelo do IGRF (International Geomagnetic Reference Field) (Barton et al., 1996) foi inicialmente removido dos dados magnetométricos originais, resultando no campo magnético anômalo (CMA). Testes de diferença quarta e parâmetros $P$ (Blum, 1999) foram aplicados para avaliação da distribuição e consistência dos dados. Em seguida, uma malha regular foi definida e os dados interpolados pelo método da curvatura mínima, mantendose um intervalo de 1/4 do espaçamento das linhas de vôo no grid (62,5 m) (Vasconcellos et al., 1994). 0 micronivelamento foi realizado pela metodologia descrita em Minty (1991). Posteriormente, foram calculadas as derivadas horizontais em $\mathrm{x}$ e y (DX e Dy), a primeira derivada vertical (DZ), as amplitudes do sinal analítico (ASA) (Roest et al., 1992) e do gradiente horizontal total (AGHT) (Cordell \& Grauch, 1985), e a inclinação (fase) do sinal analítico (ISA) (Fig. 3) (Miller \& Singh, 1994, Thurston \& Smith, 1997). A partir da delimitação de fontes magnéticas (Milligan \& Gunn, 1997) por meio da ASA, foram identificadas, de forma qualitativa, quatro classes de valores da ASA (muito alta, alta, média, baixa) em ambiente SIG (Sistema de Informações Georreferenciadas), compondo o mapa de domínios da Figura 4. Lineamentos magnéticos, interpretados com base em todas as imagens magnetométricas geradas (e.g., imagens da primeira derivada vertical (DZ), amplitude do gradiente horizontal total (AGHT), inclinação do sinal analítico (ISA) - Fig. 5), foram inseridos neste mapa para posterior interpretação litológico-estrutural da área. Diagramas de rosetas azimutais (do tipo média dos comprimentos dos lineamentos) foram gerados a partir dos lineamentos estruturais observados nas imagens de DX, DY, DZ, ASA, AGHT e ISA (Fig. 6).

Os dados gamaespectrométricos foram pré-processados analogamente aos dados magnetométricos. Destes procedimentos resultaram imagens corrigidas dos canais do $\mathrm{K}(\%)$, eTh (ppm), eU (ppm) e da contagem total (CT) (cps), além de imagens ternárias em RGB (vermelho-verde-azul) e CMY (ciano-magentaamarelo) produzidas a partir dos canais radiométricos originais.

A análise individual e integrada das imagens dos canais de radioelementos foi efetuada objetivando a discriminação dos diversos corpos geológicos da região de Serra Leste. Os canais individuais e a imagem ternária foram fundidos com dados altimétricos do SRTM para averiguação de possíveis influências do relevo na distribuiç̧ão e concentração dos radioelementos (Fig. 7). Esta etapa é fundamental no discernimento de efeitos produzidos por intemperismo químico e de transporte de materiais nas assinaturas geofísicas dos litotipos estudados. A partir dos produtos gamaespectrométricos supracitados, treze domínios ou classes, caracterizados por diferentes respostas nos canais de K (\%), eTh e eU, foram interpretados qualitativamente. A reunião destes domínios em ambiente SIG possibilitou a geração de um mapa de domínios gamaespectrométricos da área (Fig. 8). Destaca-se que os mapas de domínios geofísicos (Figs. 4 e 8) foram interpretados na escala 1:100.000.

Os depósitos de Serra Pelada (Au-Pt-Pd), Luanga (EGP-Cr), Serra Verde (Cu-Mo-Au) e Serra Leste (Fe) foram analisados de maneira quantitativa por meio da extração de suas respectivas assinaturas geofísicas (Fig. 9).

\section{RESULTADOS}

\section{Caracterização geológico-estrutural}

A partir do mapa de domínios magnéticos (Fig. 4) e dos diagramas de rosetas azimutais (Fig. 6), três padrões estruturais foram identificados na região de Serra Leste:

1) Estrutura dúctil de direção WNW-ESE, que atravessa continuamente a área de estudo. É representada pela ZCTC e indicada pelo número "1" nos diagramas de rosetas azimutais gerados a partir da interpretação das imagens das derivadas em x, y e z, da amplitude do gradiente horizontal total e da inclinação do sinal analítico. 


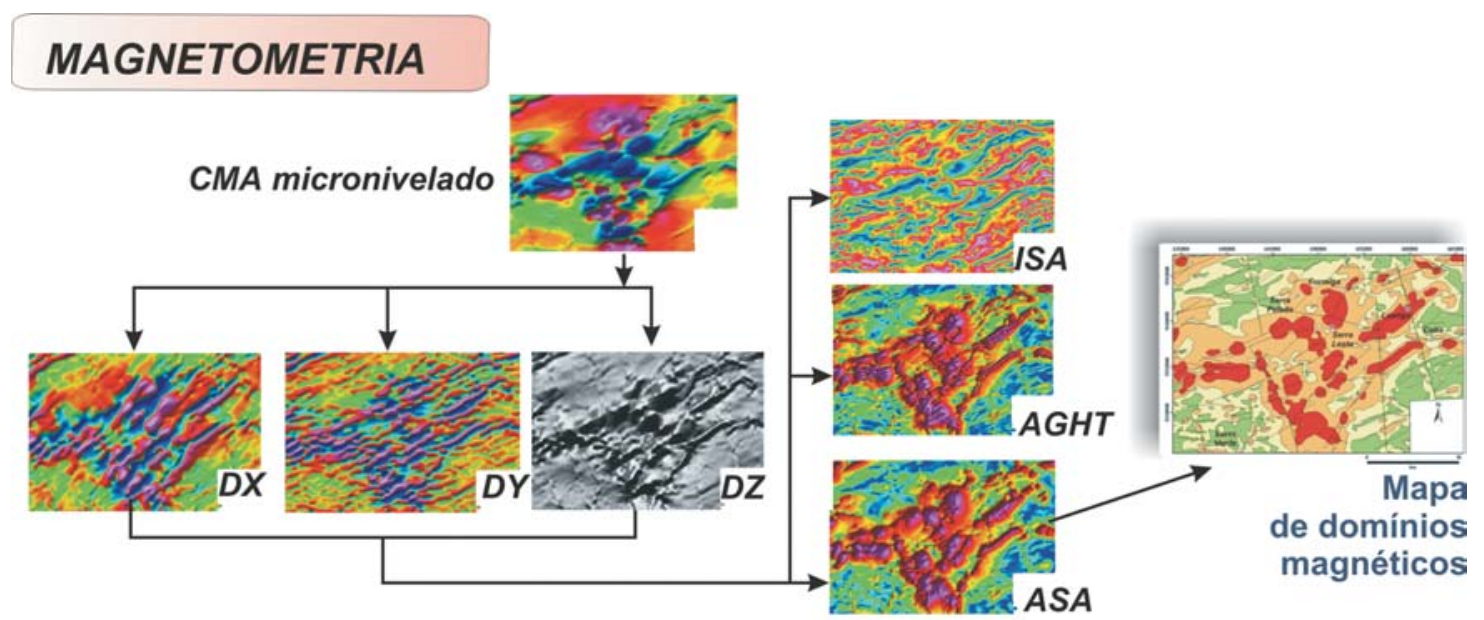

\section{GAMAESPECTROMETRIA}

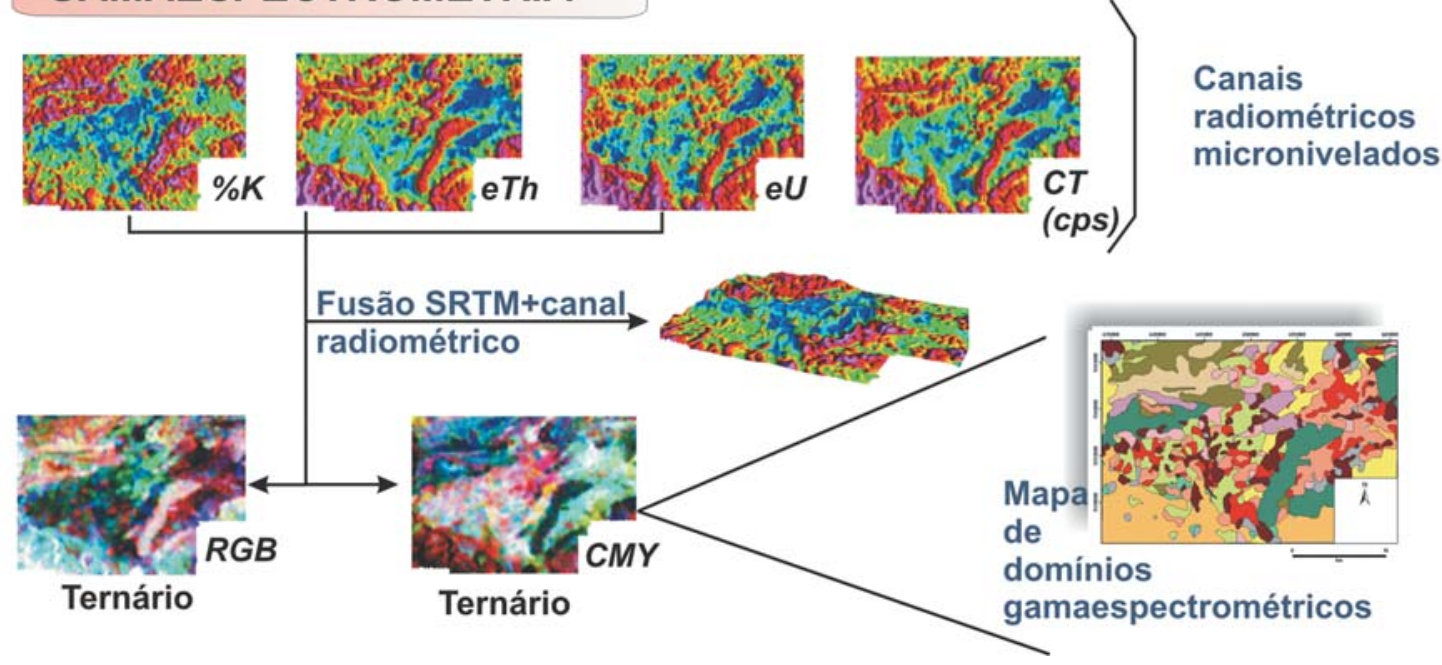

Figura 3 - Fluxograma dos métodos de investigação adotados a partir de dados magnetométricos e gamaespectrométricos. CMA - campo magnético anômalo; DX - primeira derivada horizontal em $\mathrm{x}$ do campo magnético anômalo; DY - primeira derivada horizontal em y do campo magnético anômalo; DZ - primeira derivada vertical do campo magnético anômalo; AGHT - amplitude do gradiente horizontal total; ASA - amplitude do sinal analítico; ISA - intensidade do sinal analítico; CT - canal da contagem total (cps), RGB - composição ternária das imagens de K (\%), eTh e eU, respectivamente, nos canais vermelho-verde-azul; CMY - composição ternária das imagens de $\mathrm{K}(\%)$, eTh e eU, respectivamente, nos canais ciano-magenta-amarelo.

2) Estruturas rúpteis-dúcteis de direção NE-SW, relacionadas à terminação rabo de cavalo de Serra Pelada. São indicadas pelo número "2" nos diagramas de rosetas azimutais.

3) Estruturas NNW-SSE, de grande extensão geral, associadas a diques gabro-dioríticos proterozóicos, que cortam praticamente todas as unidades da região. Tais lineamentos são assinalados com o número "3" nos diagramas de rosetas azimutais.

A Figura 5 ilustra 0 terceiro evento deformacional proposto por Veneziani et al. (2004) para a região de Carajás, a partir da movimentação sinistral observada no deslocamento dos corpos máficos/ultramáficos de Luanga e Luanga Sul, indicados, respectivamente, com os números "1" e "2". Esta fase é decorrente da reativação da ZCTC - o deslocamento dos dois corpos mencionados pode ser observado no mapa de domínios magnéticos (Fig. 4). Nota-se também que estes corpos, quando analisados individualmente, apresentam uma geometria sigmoidal, com movimentação de topo para leste e de base para oeste. Esta configuração estrutural de natureza dextral é correlata à segunda fase deformacional, de acordo com a classificação adotada em 


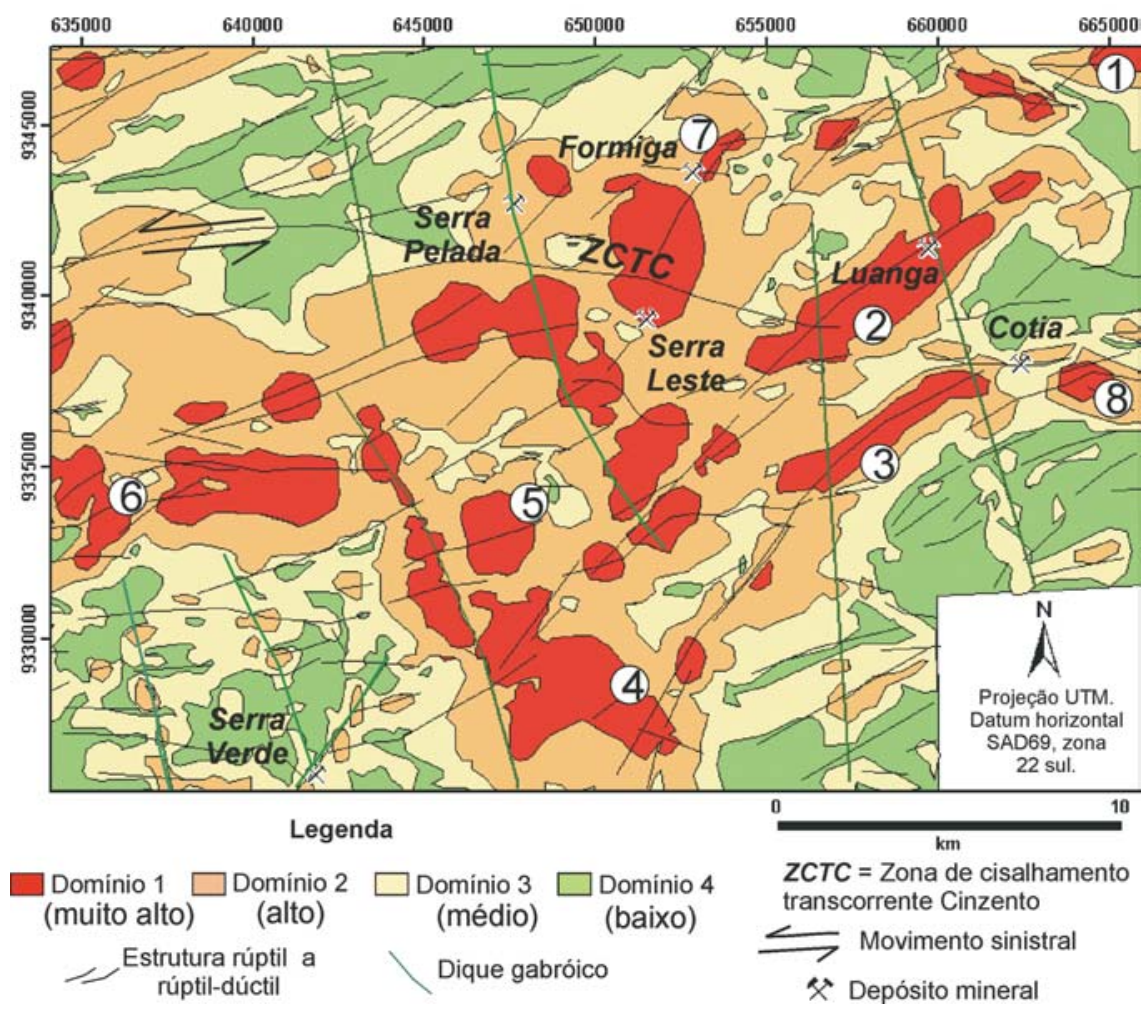

Figura 4 - Mapa de domínios magnéticos. Corpos com muito alta, alta, média e baixa resposta magnética foram segmentados em domínios 1, 2, 3, 4, respectivamente. Os lineamentos foram interpretados a partir das imagens DX, DY, DZ, ASA, AGHT e ISA. Corpos máficos/ultramáficos: 1 - Luanga Norte; 2 - Luanga; 3 - Luanga Sul; 4 - Afrodite; 5 - Órion; 6 - Centauro; 7 - Formiga; 8 - Pégasus.

Veneziani et al. (2004), e já verificada na área de estudo por outros autores (e.g., Nunes, 2002).

Os mapas de domínios magnéticos (Fig. 4) e gamaespectrométricos (Fig. 8) também permitiram identificar assinaturas geofísicas correlacionáveis a unidades litológicas pré-mapeadas (cf. , mapa geológico da Fig. 2):

1) Embasamento: de idade arqueana, é predominantemente granitóide, sendo melhor discriminado no mapa de domínios gamaespectrométricos (Fig. 8). Neste mapa, esta unidade é correlata, parcialmente, aos domínios 1 (altos \% K, eTh, eU nas porções leste e nordeste) e 8 (alto \%K, médios eTh e eU), além do domínio 13 (médios \%K e eTh, alto eU), que compreende a porção sul da área de estudo. Estas assinaturas revelam altos valores nos três radioelementos, 0 que condiz com a existência de corpos graníticos lato sensu (Dickson \& Scott, 1997), como indicado na Figura 2.

2) Grupo Rio Novo: as assinaturas geofísicas associadas a este grupo estão espacialmente dispostas na porção centro-oeste da área de estudo. De forma geral, esse setor é caracterizado por vaIores muito altos a altos da ASA (domínios 1 e 2) (Fig. 4). Dos oito complexos máficos/ultramáficos apresentados na Figura 2, alguns estão inseridos nesta unidade (cf., Fig. 4). 0 mapa de domínios gamaespectrométricos (Fig. 8) evidencia este grupo por meio de respostas radiométricas variáveis, em decorrência das diversas subunidades presentes. Em parte, os domínios 2 e 3 caracterizam principalmente os corpos máficos, assim como os domínios 4, 5 e 9 para todo 0 conjunto. Nota-se que 0 caráter máfico geral do grupo é realçado por todos estes domínios gamaespectrométricos citados, os quais possuem, fundamentalmente, valores baixos a médios de \% $\mathrm{K}$, eTh e eU.

3) Complexo Luanga: caracterizado no mapa de domínios gamaespectrométricos por baixos valores de \%K, eTh, eU (domínio 2) e, subordinadamente, por alto \%K, baixos eTh e eU (domínio 3). Estas assinaturas são típicas de rochas máficas/ultramáficas (Dickson \& Scott, 1997). 0 domínio magnético 1 (Fig. 4) corrobora os dados gamaespectrométricos, uma vez que denota valores muito altos da ASA devido à composição das 


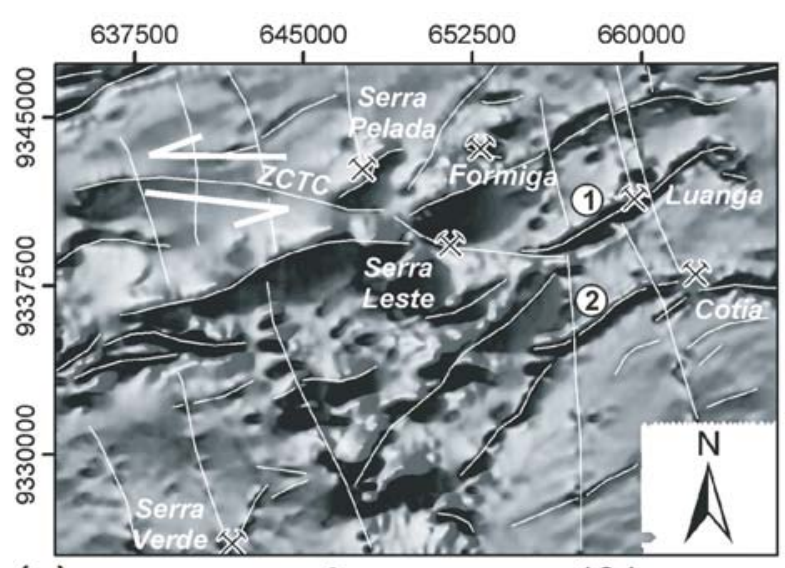

(a)
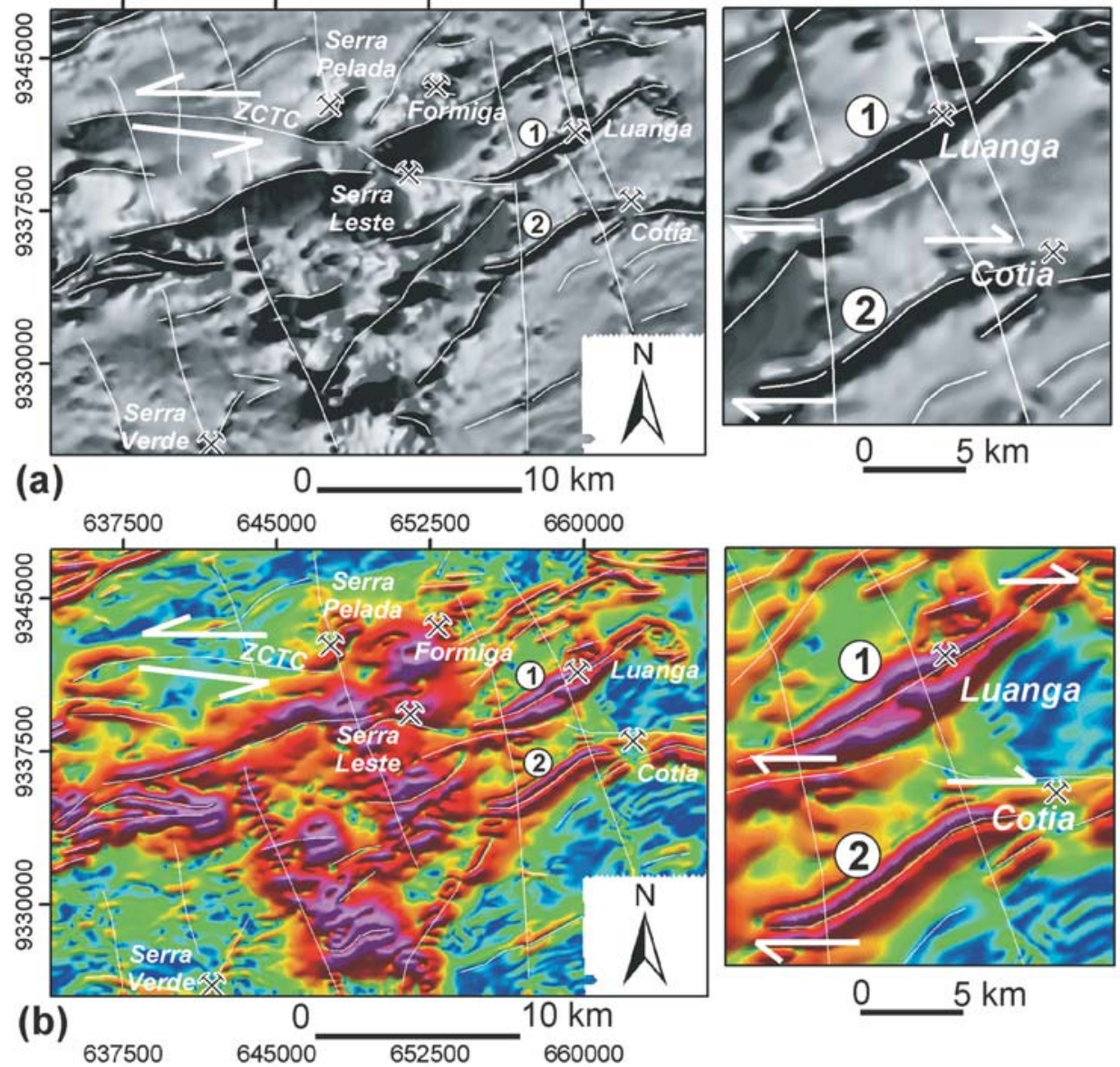

\section{$\mathrm{DZ}(\mathrm{nT} / \mathrm{m})$}

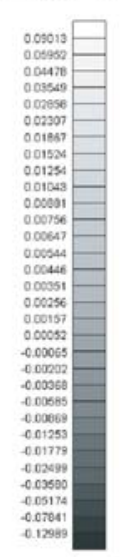

$\mathrm{AGHT}(\mathrm{nT} / \mathrm{m})$
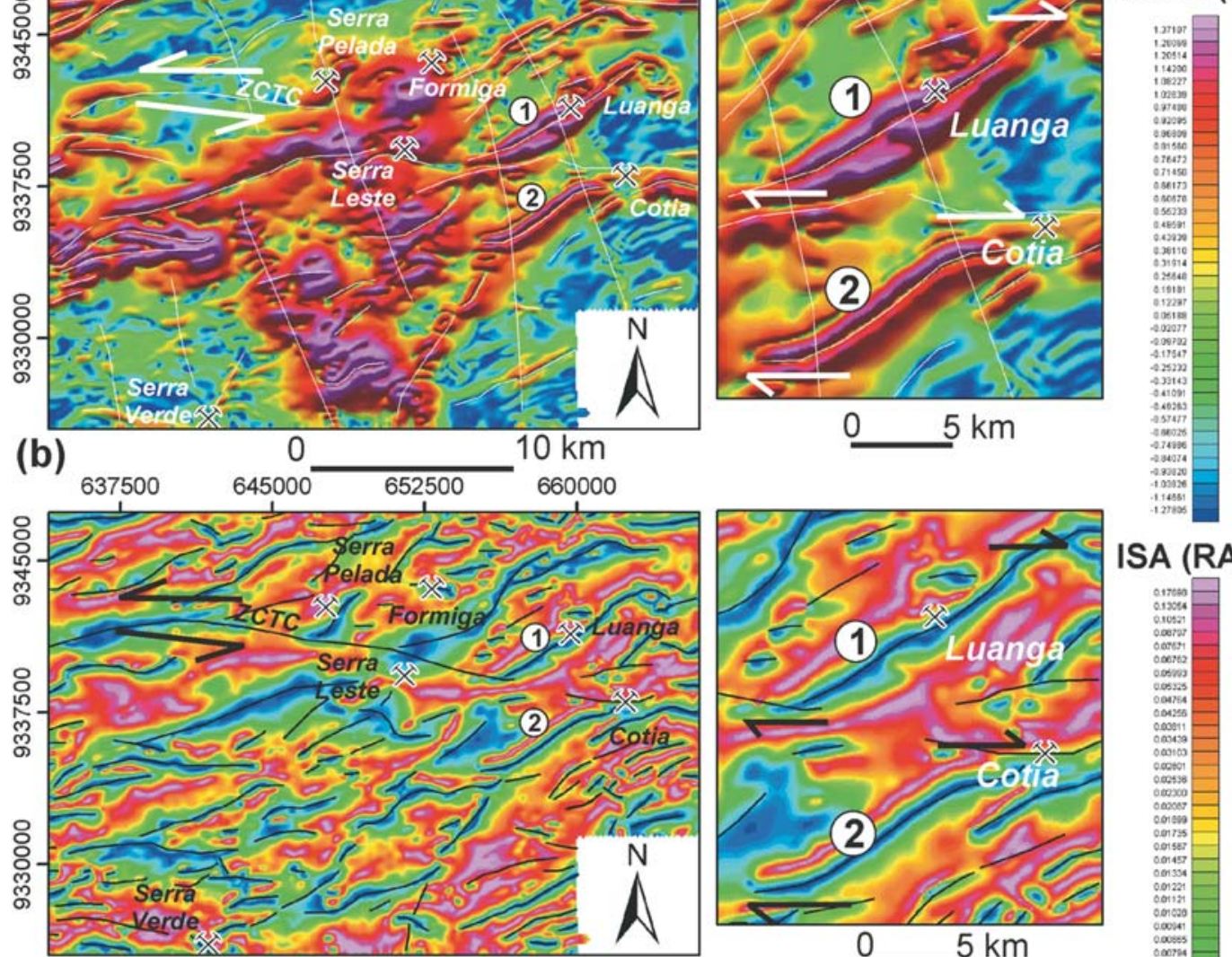

(c)

0

$10 \mathrm{~km}$

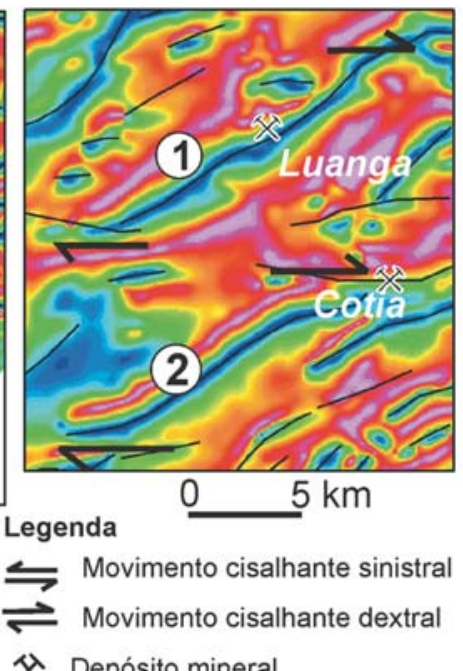

ISA (RAD)

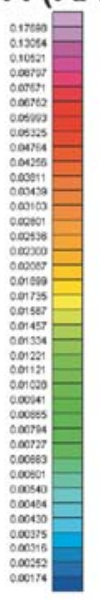

Figura 5 - À esquerda, imagens da primeira derivada vertical (DZ) (a), da amplitude do gradiente horizontal (AGHT) (b) e da inclinação do sinal analítico (c) que exemplificam o movimento sinistral da ZCTC ( $c f$., setas pretas e brancas indicadas), marcado pelo deslocamento dos corpos 1 (Luanga) e 2 (Luanga Sul), compreendidos no complexo homônimo. As estruturas de tendência NNW-SSE e marcadas em geral por grande extensão, representam os principais diques gabróicos da região (cf., Fig. 4). Notar que o depósito de Serra Leste mostra-se afetado pela instalação de diques. À direita, a análise individual dos corpos 1 (Luanga) e 2 (Luanga Sul) permitiu a verificação do formato sigmoidal dos mesmos, indicando movimentação dextral e que corresponde a uma fase de movimentação distinta da anterior. 


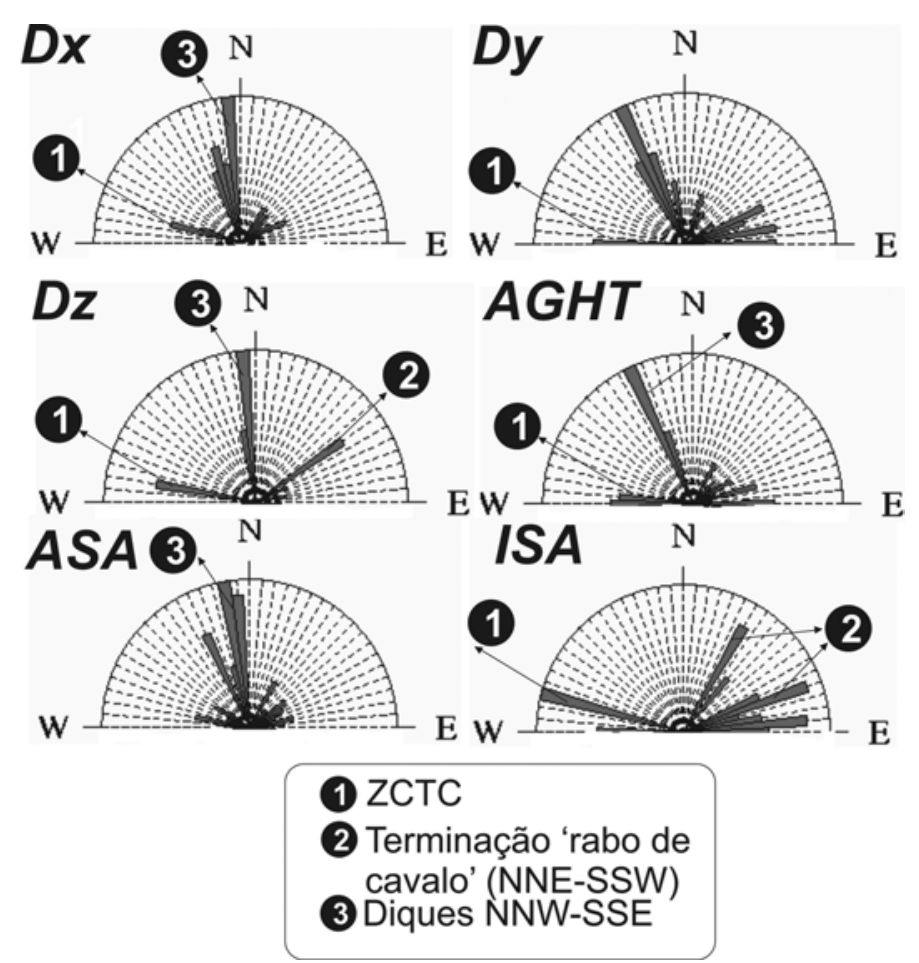

Figura 6 - Rosetas azimutais derivadas da interpretação de lineamentos nas imagens de DX (derivada horizontal em x), DY (derivada horizontal em y), DZ (derivada vertical), AGHT (amplitude do gradiente horizontal total), ASA (amplitude do sinal analítico) e ISA (inclinação do sinal analítico).

rochas máficas e ultramáficas e de seus equivalentes alterados (e.g., magnetita gerada da alteração de olivinas). Estes valores também são similares aqueles verificados em áreas com predomínio de rochas do Grupo Rio Novo. Os complexos máficoultramáficos Luanga Norte (1), Luanga (2) e Luanga Sul (3) foram bem delimitados nos mapas de domínios geofísicos (Figs. 4 e 8).

4) Formação Águas Claras: os domínios gamaespectrométricos 6 (alto \%K, médio eTh, baixo eU) e 7 (médios \%K e eTh; baixo eU), espacialmente, mostram relações com quartzitos e metapelitos/carbonatos desta formação, compondo as serranias observadas na Figura 7. A distinção entre estes domínios ocorre por pequena variação em potássio, estando estes corpos localizados preferencialmente na porção noroeste da área de estudo, o que é correlato com os dados geológicos disponíveis (Fig. 2).

5) Complexo Granítico Estrela: mostra-se indiviso no domínio gamaespectrométrico 1 , com área de abrangência na porção nordeste. Os altos valores nos três radioelementos corroboram a existência deste litotipo.

6) Granitos anorogênicos: 0 Granito Cigano pôde ser discriminado a partir do domínio gamaespectrométrico 1 que o limita na porção noroeste da área de estudo. Entretanto, partes dos granitos arqueanos também mostram-se pertencentes a este mesmo domínio, como observado nas porções sudeste e nordeste da área (altos valores de \%K, eTh, eU).

7) Diques: de natureza geral gabro-diorítica, apresentam-se pouco delimitáveis nas imagens magnetométricas em virtude de possuírem direção praticamente paralela à das linhas de vôo. Por tal fato, o mapa de domínios magnetométricos permitiu evidenciá-los somente de maneira discreta.

8) Coberturas supergênicas: relacionadas a altos valores nos canais de eTh e mais subordinadamente de $\mathrm{U}$, quando estes apresentam-se associados a áreas de platôs serranos - uma condição propícia à geração de mantos intempéricos expressivos. Este fato pode ser observado com mais clareza na Figura 7, em perspectiva. Áreas correlacionáveis ao domínio gamaespectrométrico 12 (alto eTh, baixos \% e eU) mostram associação a coberturas supergênicas (TQDL), da mesma forma que parte do domínio 4 (alto eU, baixos \% e Teh), quando este mostrase associado a áreas de platôs serranos. A disposição espacial destes domínios ilustra a influência do relevo na distribuição de radioelementos, principalmente em terrenos com intenso intem- 

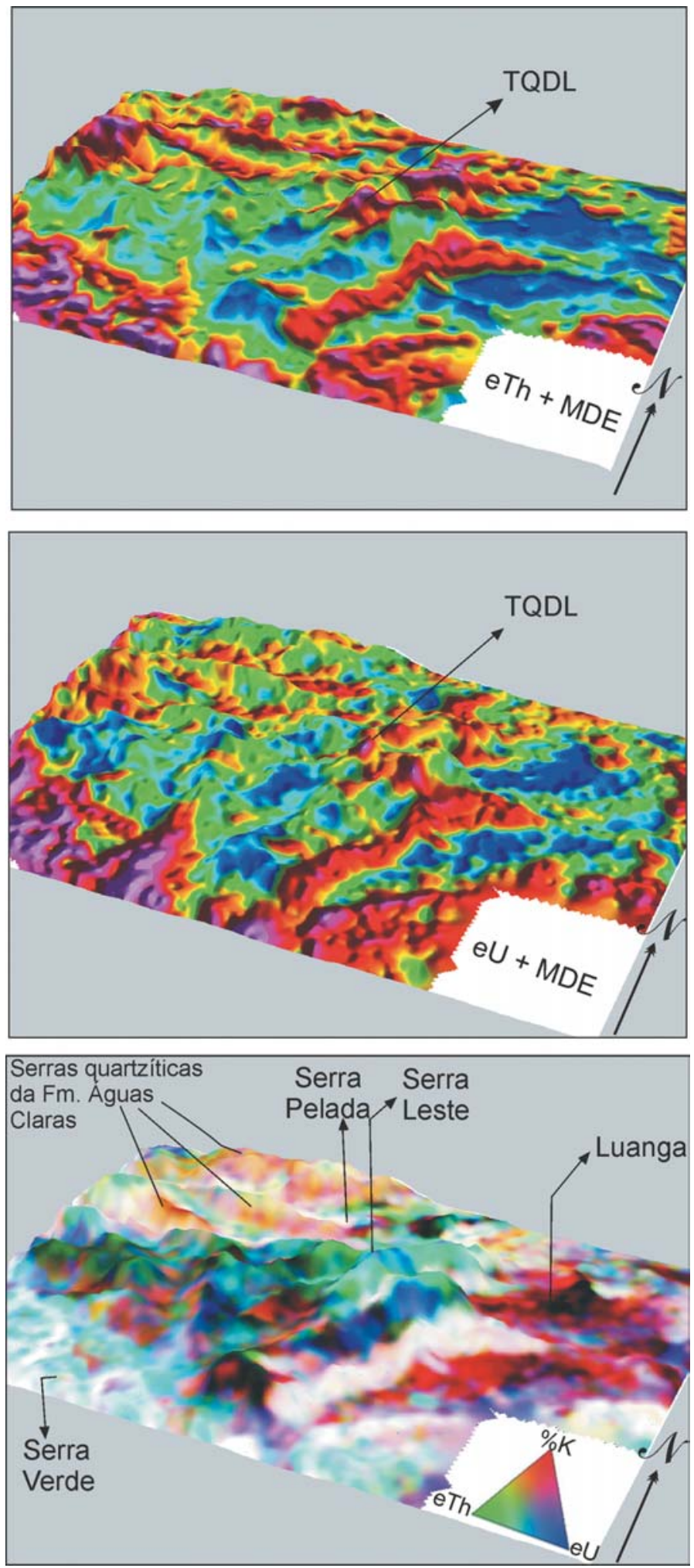

Figura 7 - Fusão do modelo digital de elevação (MDE) do SRTM com os canais do eTh e eU, e com a imagem ternária (RGB). Observa-se que os altos valores de eTh e eU estão associados à área de platô e correlacionados com coberturas supergênicas (TQDL) (cf. mapa da Fig. 2). 


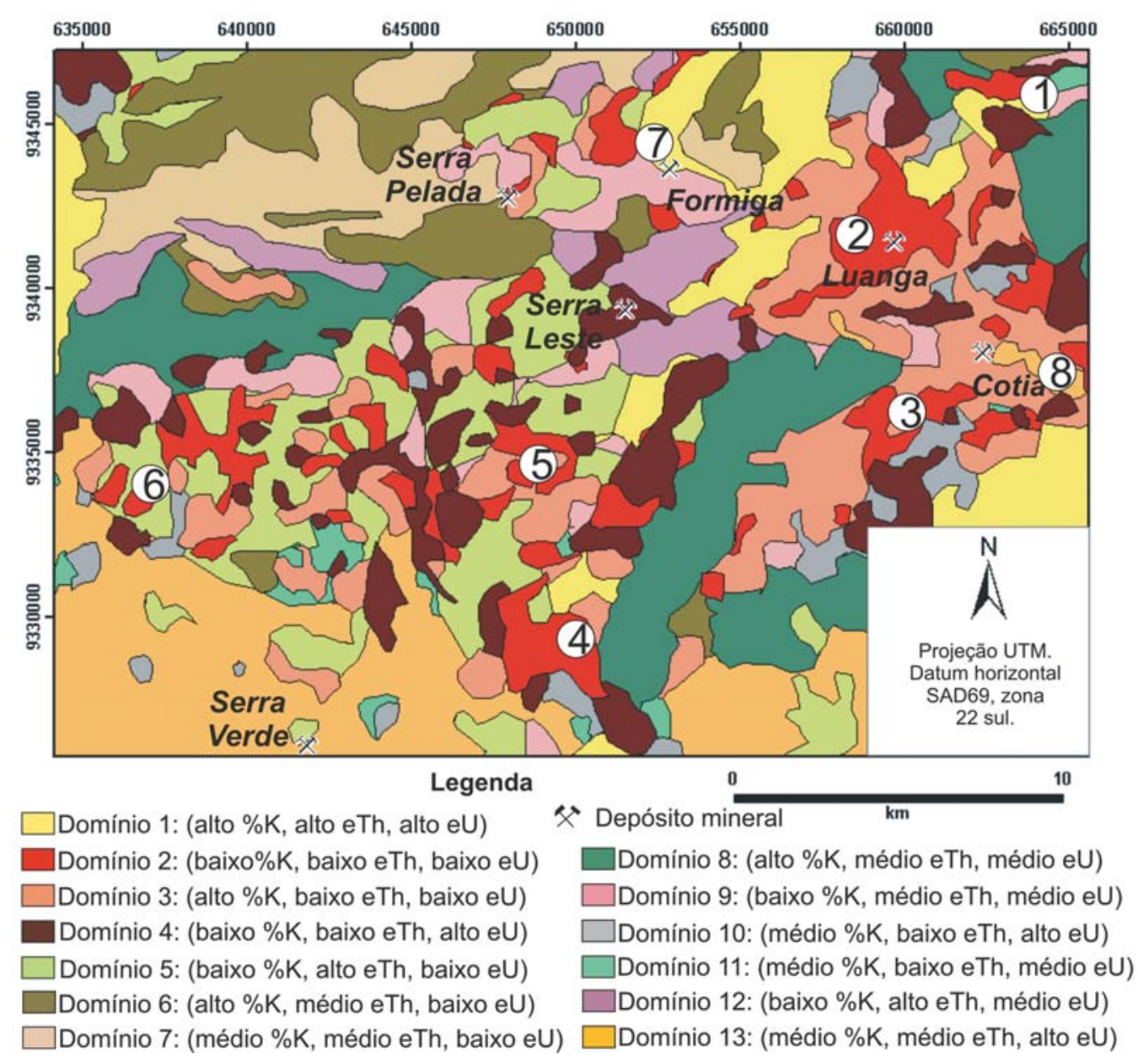

Figura 8 - Mapa de domínios gamaespectrométricos interpretados a partir das imagens ternárias em RGB e CMY, e canais de K (\%), eTh, eU individuais ou compostos com os dados altimétricos do SRTM. Corpos máficos/ultramáficos são apresentados em: 1 - Luanga Norte; 2 - Luanga; 3 - Luanga Sul; 4 - Afrodite; 5 - Órion; 6 - Centauro; 7 - Formiga; 8 - Pégasus.

perismo químico. Também mostram que a interpretação de superfícies de natureza supergênicas requer cautela, e que os MDEs do SRTM podem ser utilizados com vantagens para a sua melhor caracterização.

\section{Caracterização de prospectos}

A caracterização de prospectos foi efetuada com base nos mapas de domínios geofísicos (Figs. 4 e 8) para os depósitos do tipo Serra Pelada, Luanga, Serra Verde e Serra Leste, e de suas respectivas assinaturas geofísicas (Fig. 9).

1) Serra Pelada: deste depósito de Au-Pt-Pd situa-se na convergência dos domínios gamaespectrométricos 3 (alto \%K, baixos eTh e eU), 6 (alto \%K, médio eTh, baixo eU) e 7 (médio \% K e eTh, baixo eU) associados à Formação Águas Claras, e por corpos menos extensos dos domínios 2 e 3 , relacionados a ro- chas máficas/ultramáficas dispostas nas porções nordeste e noroeste. Estes corpos podem constituir as rochas-fontes de EGP, como já postulado em trabalhos anteriores (e.g., Tallarico et al., 2000), visto a proximidade espacial destes com o depósito e da afinidade química destes elementos com os litotipos associados (mencionados acima). Somado a estas considerações, o mapa de domínios magnéticos (Fig. 4) apresenta altos valores nesta área, 0 que torna ainda mais condizente a existência próxima ao depósito de possível(is) corpo(s) de composição máfica/ultramáfica. 0 pequeno corpo definido a nordeste do depósito, de acordo com o mapa gamaespectrométrico (domínio 2), está correlacionado ao domínio 1 da Figura 4 (valores da ASA muito alta), por exemplo. A existência de diques gabróicos NNW-SSE individualizados em imagens magnetométricas, como a da primeira derivada vertical e da amplitude do gradiente horizon- 

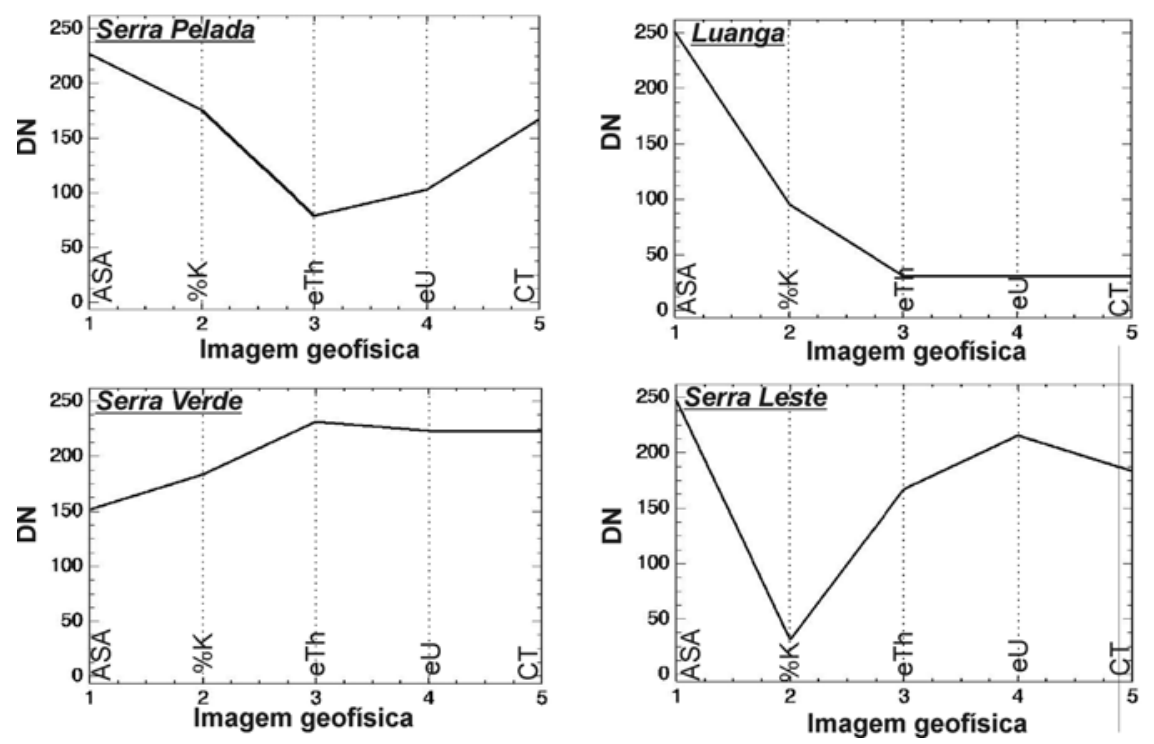

Figura 9 - Assinaturas geofísicas dos depósitos de Serra Pelada (Au-Pt-Pd), Luanga (EGP-Cr), Serra Verde (Cu-Mo$\mathrm{Au}$ ) e Serra Leste (Fe), considerando-se as respostas nos canais de $\mathrm{K}(\%)$, eTh, eU, e contagem total (CT), e na imagem de amplitude do sinal analítico (ASA).

tal (AGHT) (cf., Fig. 5), também permite a consideração destes como rochas fonte de EGP para este depósito (e.g., Tallarico et al., 2000).

2) Luanga: neste depósito de Cr-EGP, há predomínio de assinaturas geofísicas associadas ao domínio gamaespectrométrico 2 e ao domínio magnético 1, típicos de rochas hospedeiras máficas/ultramáficas, o que corrobora os dados da literatura (Complexo Luanga, e.g., Dardenne \& Schobbenhaus, 2001). 0 depósito é hospedado pelo corpo Luanga (número 2 dos mapas de domínios magnéticos e gamaespectrométricos), caracterizado por grande expressão em área. 0 domínio gamaespectrométrico 2 possui perfaz aproximadamente $12 \%$ da área de estudo, indicando alvos potenciais mais amplos à pesquisa de mineralizações de Cr-EGP.

3) Serra Verde: este depósito de Cu-Mo-Au é destacável principalmente no mapa de domínios gamaespectrométricos (Fig. 8). Apresenta-se na abrangência do domínio 5 (alto eTh, baixos \% K e eU) de forma quase pontual, e circunscrito por granitos arqueanos associados ao domínio 13 (médios \% e eTh, alto eU). Este fato corrobora as descrições deste pequeno depósito hospedado em rochas máficas do Grupo Rio Novo que sofreu metamorfismo com a colocação posterior do Complexo Granítico Estrela (Villas \& Santos, 2001). 0 mapa de domínios gamaespectrométricos (Fig. 8) avança em detalhes no mapeamento das assinaturas intrínsecas à disposição das rochas hospedeiras/encaixantes, se comparado aos poucos trabalhos já realizados em Serra Verde (e.g., Villas \& Santos, 2001; Reis \& Villas, 2002). Ressaltase, neste mesmo mapa (Fig. 8), a presença de outros corpos com assinatura geofísica similar ao do depósito de Serra Verde. As pequenas dimensões dos mesmos e a relação de disposição similar em relação aos granitóides arqueanos intrusivos em evento posterior, podem caracterizá-los como possíveis alvos potenciais para Cu-Mo-Au.

4) Serra Leste: 0 depósito de ferro é muito bem delimitado no mapa de domínios magnéticos, marcado por altos valores da ASA (domínio 1 e mais subordinadamente 0 domínio 2). Esta é a mesma assinatura dos corpos máficos/ultramáficos neste mapa (Fig. 4). Entretanto, no mapa de domínios gamaespectrométricos (Fig. 8), ambos são diferenciados, uma vez que os baixos valores nos canais de \%K, eTh e eU não caracterizam Serra Leste, predominando neste as abrangências dos domínios 4 e 12 (respectivamente, alto eU e baixos \% e eTh; alto eTh, médio eU, baixo \% K). Altos valores no canal do eTh (e mesmo no canal do eU) são típicos de regiões marcadas por coberturas supergênicas, enriquecidas em ferro, como já reportado em Dickson \& Scott (1997), Gunn et al. (1997). Sob a ação do clima equatorial úmido da região Amazônica, os depósitos de ferro de Carajás comumente são recobertos por espessas crostas ferruginosas com diferentes graus 
intempéricos. Somado a isto, aerolevantamentos gamaespectrométricos conseguem discriminar tais superfícies, uma vez que registram a quantidade dos radioelementos dos materiais presentes a profundidades de até cerca de $30 \mathrm{~cm}$ (Dickson \& Scott, 1997). Outro fator importante compreende a localização em áreas de platôs serranos, o que favorece processos intempéricos intensos, que originam as crostas ferruginosas, como notado peIos altos valores de eTh e eU nestas condições (Fig. 7). Estas discussões e interpretações mostram adequação às informaç̃ões observadas no mapa geológico da Figura 2, que apresenta coberturas supergênicas ricas em ferro nos domínios de Serra Leste.

As interpretações das respostas geofísicas dos corpos geológicos portadores de mineralizações (Figs. 4 e 8) são suportadas resultados quantitativos mostrados na Figura 9.

\section{CONCLUSÕES}

Nesse estudo de caso foi possível discutir e demonstrar que dados aerogeofísicos, quando pré-processados adequadamente, funcionam como ferramentas para reconhecimento de tramas estruturais e litológicas complexas, incluindo aproximações robustas para seleção de alvos de interesse metalogenético. Estas contribuições são fundamentais em regiões sob forte intemperismo químico, caso das áreas equatoriais úmidas como Serra Leste, caracterizadas por poucos afloramentos litológicos e dificuldades de acesso. Ressalta-se, entretanto, a necessidade de cautela para a interpretação sobre a natureza da concentração de radioelementos, principalmente em cenários condicionados por relevos favoráveis à atuação de intemperismo químico. Essas considerações, somadas aos bons resultados obtidos neste estudo de caso, confirmam a excelência de dados aerogeofísicos nas investigações geológicas, motivando pesquisas de mapeamento regional//ocal e de exploração mineral com base nas geotecnologias.

\section{AGRADECIMENTOS}

T.A. Carrino e E.P. Leite agradecem à FAPESP (Fundação de Amparo à Pesquisa do Estado de São Paulo) pela concessão, respectivamente, da bolsa de iniciação científica (proc. $n^{\circ}$ 2006/ 02566-8) e da bolsa de pós-doutorado (proc. n 2005/04453-3). C.R. de Souza Filho agradece à FAPESP pelo auxílio financeiro à pesquisa (procs. nos 2003/09916-6 e 2002/09038-6) e ao CNPq pela bolsa de Produtividade em Pesquisa.

\section{REFERÊNCIAS}

ALMEIDA T, SOUZA FILHO CR, ABREU FR \& CRÓSTA AP. 2003. Modelo exploratório para a prospecção de depósitos de Zn-Pb utilizando dados de alta resolução espacial e espectral do sensor GEOSCAN MKIl: estudo de caso no depósito Salobro, Porteirinha (MG). Rev. Bras. Geoc., 33(2-Suplemento): 5-16.

BARROS CEM, SARDINHA AS, BARBOSA JPO, KRIMSKI R \& MACAMBIRA MJB. 2001. Pb-Pb and U-Pb zircon ages of Archean syntectonic granites of the Carajás metallogenic province, northern Brazil. South American Symposium on Isotopic Geology. 3. Extended Abstract Volume, Pucón, Chile, 94-97.

BARTON CE, BALDWIN RT, BARRACLOUGH DR, BUSHATI S, CHIAPPINI M, COHEN Y, COLEMAN R, HULOT G, KOTZ ER, GOLOVKOV VP, JACKSON A, LANGEL RA, LOWES FJ, MCKNIGHT DJ, MACMILLAN S, NEWITT LR, PEDDIE NW, QUINN JM \& SABAKA TJ. 1996. International Geomagnetic Reference Field. 1995 Revision. IAGA Division V. Working Group 8, Phys. Earth Planet. Inter., 97: 23-26.

BLUM MLB. 1999. Processamento e interpretação de dados de geofísica aérea no Brasil central e sua aplicação à geologia regional e à prospecção mineral. Tese de Doutorado, Universidade de Brasília, Brasília-DF, $229 \mathrm{pp}$.

CORDELL L \& GRAUCH VJS. 1985. Mapping basement magnetization zones from aeromagnetic data in the San Juan basin, New Mexico. In: HINZE WJ. (Ed.). The Utility of Regional Gravity and Magnetic Anomaly Maps, Society of Exploration Geophysicists, 181-197.

CRÓSTA AP, SOUZA FILHO CR, AZEVEDO F \& BRODIE C. 2003. Targeting key alteration minerals in epithermal deposits in Patagonia, Argentina, using ASTER imagery and principal component analysis. International Journal of Remote Sensing, 24(21): 4233-4240.

CVRD. Companhia Vale do Rio Doce. 2007. Disponível em: $<$ www.curd.com.br >. Acesso em: 8 mar. 2007.

DALL'AGNOL R, LAFON JM \& MACAMBIRA MJB. 1994. Proterozoic anorogenic magmatism in the Central Amazonian Province, Amazonian Craton: geochronological, petrological and geochemical aspects. Mineral. Petrol., 50: 113-118.

DALL'AGNOL R, SOUZA ZS, ALTHOFF FJ, BARROS CEM, LEITE AAS \& JORGE-JOÃO XS. 1997. General aspects of the granitogenesis of the Carajás metallogenetic province. Proceedings of the International Symposium on Granites and Associated Mineralizations, Salvador, Excursion Guide, 135-161.

DARDENNE MA \& SCHOBBENHAUS C. 2000. The metallogenesis of the South American platform. In: CORDANI UG, MILANI EJ, THOMAZ FILHO A \& CAMPOS DA. (Ed.). Tectonic Evolution of South America. 31 $1^{\text {st }}$ International Geological Congress, 755-850, Rio de Janeiro-RJ.

DARDENNE MA \& SCHOBBENHAUS C. 2001. Metalogênese do Brasil. Ed. UnB, Brasília-DF, 78-83. 
DICKSON BL \& SCOTT KM. 1997. Interpretation of aerial gamma-ray surveys - adding the geochemical factors. AGSO Journal of Australian Geology and Geophysics, 17(2): 187-200.

DOCEGEO. Rio Doce Geologia e Mineração S.A. 1988. Revisão litoestratigráfica da Província Mineral de Carajás. Anais XXXV Congr. Bras. Geol., 11-56, Belém-PA.

GUNN PJ, MAIDMENT D \& MILLIGAN PR. 1997. Interpreting aeromagnetic data in areas of limited outcrop. AGSO Journal of Australian Geology and Geophysics, 17(2): 175-185.

LINDENMAYER ZG, LAUX JH \& TEIXEIRA JBG. 2001. Considerações sobre a origem das formações ferríferas da Formação Carajás, Serra dos Carajás. Rev. Bras. Geoc., 31(1): 21-28.

MARSCHIK R, MATHUR R, RUIZ J, LEVEILLE R \& ALMEIDA AJ de. 2005. Late Archean Cu-Au-Mo mineralization at Gameleira and Serra Verde, Carajás Mineral Province, Brazil: constraints from Re-0s molybdenite ages. Mineralium Deposita, 39: 983-991.

MILLER HG \& SINGH V. 1994. Potential Field Tilt - a new concept for Iocation of potential field sources. Journal of Applied Geophysics, 32: 213-217.

MILLIGAN PR \& GUNN PJ. 1997. Enhancement and presentation of airborne geophysical data. AGSO Journal of Australian Geology and Geophysics, 17(2): 63-75.

MINTY BRS. 1991. Simple micro-levelling for aeromagnetic data. Exploration Geophysics, 22: 591-592.

NUNES AR. 2002. Análise de dados geológicos, geofísicos e de sensoriamento remoto para geração de modelos prospectivos para a região de Serra Leste, Carajás (PA). Dissertação de Mestrado, Instituto de Geociências, Universidade Estadual de Campinas, Campinas-SP, 132 pp.

PINHEIRO RV \& HOLDSWORTH R. 2000. Evolução tectono-estratigráfica dos sistemas transcorrentes Carajás e Cinzento, Cinturão Itacaiúnas, borda leste do cráton Amazônico, Pará. Rev. Bras. Geoc., 30(4): 597-606.
REIS FN \& VILLAS RN. 2002. Mineralização e alteração hidrotermal no depósito cupro-aurífero de Serra Verde, Província Mineral de Carajás. Rev. Bras. Geoc., 32(1): 69-86.

ROEST WR, VERHOEF J \& PILKINGTON M. 1992. Magnetic interpretation using the 3-D analytic signal. Geophysics, 57(1): 116-125.

SILVA AM, PIRES ACB, MaCCAFFERTY A, MORAES RAV de \& XIA H. 2003. Application of airborne geophysical data to mineral exploration in the uneven exposed terrains of the Rio das Velhas Greenstone Belt. Rev. Bras. Geoc., 33(2-Suplemento): 17-28.

SOUZA FILHO CR \& CRÓSTA AP. 2003. Geotecnologias aplicadas à GeoIogia. Rev. Bras. Geoc., 33(2-Suplemento): 1-4.

SUITA MTF. 1988. Geologia da área Luanga com ênfase na petrologia do complexo básico-ultrabásico Luanga e depósitos de cromita associados, Pará. Dissertação de Mestrado, Universidade de Brasília, Brasília-DF, $320 \mathrm{pp}$.

TALLARICO FHB, COIMBRA CR \& COSTA CHC. 2000. The Serra Leste sediment-hosted Au-(Pd-Pt) mineralization, Carajás Province. Rev. Bras. Geoc., 30(2): 226-229.

THURSTON JB \& SMITH RS. 1997. Automatic conversion of magnetic data to depth, dip and susceptibility contrast using the SPITM method. Geophysics, 62: 807-813.

VASCONCELLOS RM, METELO MJ, MOTTA AC \& GOMES RD. 1994. Geofísica em levantamentos geológicos no Brasil, CPRM, Rio de Janeiro, $165 \mathrm{pp}$.

VENEZIANI P, SANTOS AR \& PARADELLA WR. 2004. A evolução tectono-estratigráfica da Província Mineral de Carajás: um modelo com base em dados de sensores remotos orbitais (SAR-C RADARSAT-1, TM LANDSAT-5), aerogeofísica e dados de campo. Rev. Bras. Geoc., 34(1): 67-78.

VILLAS RN \& SANTOS MD. 2001. Gold deposits of the Carajás mineral province: deposit type and metallogenesis. Mineralium Deposita, 36: 300-331.

\section{NOTAS SOBRE OS AUTORES}

Thais Andressa Carrino. Geóloga formada pela Universidade Estadual de Campinas (2007). As áreas de interesse estão relacionadas ao uso de sensoriamento remoto multiespectral e SAR, aerogeofísica e sistemas de informações georreferenciadas para estudos de favorabilidade mineral e mapeamento geológico, além da aplicação de métodos geoestatísticos e dados de perfis geofísicos à caracterização de reservatórios petrolíferos.

Carlos Roberto de Souza Filho. Engenheiro Geólogo (UFOP, 1988), Mestre em Metalogênese (UNICAMP, 1991), PhD (Open University, Inglaterra, 1995), JovemPesquisador (FAPESP-UNICAMP, 1995-1997), Professor-Doutor (UNICAMP, 1997-2002). Desde 2002, é Livre Docente do DGRN-IG-UNICAMP. Atualmente é Coordenador do Programa de Pós-graduação de Geociências, líder do Grupo de Geotecnologias do IG, pesquisador Nível 1B do CNPq e da NASA (programas ASTER e Mars-Earth Analogs), e Editor-Associado da Revista Computers \& Geosciences. Sua área de interesse é em Mapeamento Geológico e Exploração Mineral e Petrolífera com base em dados e métodos de Sensoriamento Remoto, Aerogeofísica e Sistemas de Informações Georreferenciadas.

Emilson Pereira Leite. Pesquisador Colaborador do DGRN-IG-UNICAMP, obteve seu doutorado em Geofísica pelo IAG/USP, com estágio no Department of Earth and Space Science and Engineering da Universidade de York em Toronto, Canadá. Suas principais áreas de interesse são métodos potenciais, inversão de dados geofísicos, sensoriamento remoto e integração de dados geofísicos e geológicos para mapeamento de potencial mineral. 